\title{
Valuing difference in students' culture and experience in school science lessons
}

\author{
Indira Banner ${ }^{1}$
}

Received: 18 January 2016/Accepted: 22 January 2016/Published online: 2 August 2016

(C) The Author(s) 2016. This article is published with open access at Springerlink.com

\begin{abstract}
Susan Harper writes about how a cross-cultural learning community can be formed where people from different cultures are not simply assimilated into a school science community but are seen and heard. This makes learning reciprocal and meaningful for both recent refugees and the dominant population. Although maybe not refugees, students from poorer backgrounds in many countries are less likely to choose science at a post-compulsory level. This article discusses some of the potential barriers that are faced by many of these students, that prevent them from participating in school science. It suggests how people involved in school science might address these issues to allow a smoother cultural border crossing between the students' cultures and school science culture by reducing the significance of the crossing.
\end{abstract}

Keywords Inclusion · Cultural capital - Identity · Border crossing · Relevance

In her article Keystone characteristics that support cultural resilience in Karen refugee parents, Susan Harper demonstrates the importance of a cross-cultural learning community, that includes parents, children and schools, for effective and embodied science learning for the whole school and wider community. This leads to a climate of shared learning where Karen culture is not assimilated into the dominant culture of (school) science but is articulated and heard, making learning reciprocal, and therefore meaningful

Lead Editor: M. Reiss.

This review essay addresses issues raised in Susan Harper's paper entitled: Keystone characteristics that support cultural resilience in Karen refugee parents. doi:10.1007/s11422-015-9681-9.

Indira Banner

i.banner@education.leeds.ac.uk

1 School of Education, University of Leeds, Leeds LS2 9JT, UK 
to the Karen refugees. The Karen culture becomes a valued and valuable part of learning and the families then are not victims but actors in the children's education. This is particularly important for refugee families who may struggle to maintain their identity, and try to fight assimilation into their new environment in order to preserve it.

The study identifies a number of approaches towards an inclusive science education that could be explored, not only with refugees but with other marginalised groups within a society. This is not to detract from the very complex and disturbing issues particular to many refugees, rather to accept that working with cultural differences, rather than against them (as in Harper's description of the Hmong teacher believing her culture was a barrier to science learning) potentially allows for a greater participation and engagement in school science. Harper refers to Pierre Bourdieu's ideas of cultural capital (1977) and Glen Aikenhead's cultural border crossing (1997), as well as the importance of cultural identity and identity as a science learner. These ideas, in the context of science education, in England for example, have resonance for teachers and schools with refugee and immigrant children and also for those schools who have children from backgrounds of low socioeconomic status (SES), or even girls.

\section{Cultural border crossing}

In England, children from lower SES backgrounds tend not to attain as highly in science examinations as children from higher SES backgrounds (Homer et al. 2011). If there is a 'choice' as to which science course or route to follow then the majority of children from lower SES backgrounds are entered for science courses that traditionally are seen as having a lower academic standard (e.g. applied science courses) (Homer et al. 2013). This results in fewer children from lower SES and other backgrounds, such as many minority ethnic groups and girls, taking post-compulsory science courses (JCQ 2014), particularly physics, which over the past few years has sparked concerns in some quarters about the supply of scientists (Royal Society 2011). There has been some discussion as to the extent of the legitimacy of this argument (Smith and Gorard 2011); however, there does appear to be an issue surrounding equality of access to subjects like post-compulsory physics for certain groups of students. The main reason given for the disparity in participation between, for example, students from low SES backgrounds and those who are not, is attainment, and the major factor that predicts attainment at age 16 is prior attainment.

There are different arguments about the reasons for the attainment 'gap'; some have a basis in what Harper refers to as a deficit model of parenting, where "socially disadvantaged [parents] (...) tend to have low aspirations for themselves and their children" (Gutman and Akerman 2008, p. i) although some attempts at accounting for this difference are given. It has been estimated that parental aspirations can have a positive influence on students' attainment, in some cases equivalent to four terms of progression (Strand 2007). More recent research from the Joseph Rowntree Foundation indicates that contrary to this assumed view, families from disadvantaged backgrounds do have high aspirations for their children, as do the children themselves (Kintrea et al. 2011). Thinking about reasons for these high aspirations often being unrealised is perhaps a more helpful place to start and, like with the Karen people, instead of working against a negative or deficient image of working class families and dealing with perceived faults, there could be an inclusive attitude towards science education. This would be where teachers recognise that students in school have to negotiate cultural border crossings when they move from their 'life-world' 
to that of school science (Aikenhead 1996) and therefore a cross-cultural approach to science education, connecting school science to students' life-worlds, with an input from parents, would be most effective in advancing science knowledge and understanding. Like the Karen people feeling they were being assimilated into the dominant culture of science, so students from lower SES backgrounds can feel that their views are not important or valid and that rather than being enculturated into the school science world, they must be assimilated into it (Aikenhead and Jegede 1999). This is where communities may push back or try to resist assimilation into the dominant culture in order to maintain their identities (Harper 2015). Parents may not be easy to engage and their school science knowledge or skills may not be immediately evident, but there are other ways to engage students and their families that perhaps don't rely on a direct link to science.

Science learning is not just about what students know about science but also how to be a part of the science world and how to actually 'do' science (Barton et al. 2008). This involves a new and complex vocabulary where everyday words sometimes take on new and specific meanings. There is also the issue of (academic) literacy and not being able to access general explanations of phenomena in science as well the science-related keywords (Claussen and Osborne 2013). The importance of language and talk in teaching is clear in developing students' ideas (Scott et al. 2007) and 'doing' science also supports students' development of science words into science concepts where a deep understanding of the vocabulary shows how students link the keywords to other situations and how to use them to explain ideas accurately (Haug and Ødegaard 2014). If this is not taught well then students can feel isolated in their science lessons; Patchen and Cox-Petersen (2008, p. 995) describe some young students' experiences of science education as being "often unrecognizable or incomprehensible for students from different ethnic, linguistic, or class backgrounds".

Difference in ethnic, linguistic and class backgrounds between teachers and students, in England for example, which may have a detrimental effect on students' learning, happen because the workforce reflects the dominant educational culture. If students come into a class which has an alien capital it is much harder for them to cross borders into the new world; meanwhile, students who come from that culture will more easily gain from it (Claussen and Osborne 2013). The large majority of teachers in England (nearly $90 \%$ ), for example, are white (Department for Education 2015) and given the qualifications needed to teach science in secondary school the majority of teachers are likely also to be from middle class backgrounds. This may be very different from a teacher's students. However, this discrepancy is similar to descriptions of scientists from the past that may feature in science education. It is indeed similar to many children's apparent perceptions of scientists, as depicted by Einstein-type figures, when asked to draw a scientist (Schibeci 2006). A brief discussion of the value of the Draw A Scientist Test (DAST) suggests that if viewed with caution the DAST is still a potential indicator of what students imagine scientists are like (ibid.). More recently, from a small scale study in Turkey, it was found that students from higher SES backgrounds were less likely to draw the stereotypical male scientist whereas students from a lower SES were (Buldu 2006). In addition, Schibeci (2006) reviewed many articles indicating that the number of female scientists drawn by female students has increased in more recent studies. This view of scientists as 'other', matching with a view of science teachers in the same way, may be a factor in the border-crossing that students have to do to enter the school science world. 


\section{Cultural capital}

Recent research from the Science Aspirations and Careers Choice (ASPIRES) project has shown that students tend to have high aspirations although not necessarily for science (Archer et al. 2012). Cultural capital with relation to school science is important; Archer and her colleagues have called this 'science capital' and it tends to be greater in middle class families. This is linked to understanding what it means to 'do' science and be a scientist. This is supported by Mujtaba and Reiss (2013) in the UPMAP project who found that students who chose to go into science-related post-compulsory courses tended to have had one or more significant adults who had generated an interest or encouraged them in some way. In linked research, from the EISER project (Banner and Ryder 2014), when some students were asked about to which careers having science qualifications would lead, the answers were to be a scientist, a doctor or a science teacher; this is also documented by Archer et al. (2010) and suggests that students can have very limited views about the use of science in their professional lives.

Students and their families without much science capital may have high aspirations (including in science) but be unable to support students in their decisions and choices because of being unaware of pathways, appropriate decisions and careers that come out of studying science (Archer et al. 2010; Carter-Wall and Whitfield 2012). This was evident in recent research in a secondary school in England where many of the students interviewed, in their final year of compulsory education, talked about having career aspirations that were varied and challenging (which could be described as high) but some of the students were not apparently aware of whether any or what type of post-compulsory study was necessary or how to negotiate and navigate getting there (Banner in prep). It is not surprising that being unaware of career goals or ways of achieving those goals influence what students think about when post-compulsory choices are made and limit possible choice (Aschbacher et al. 2010). Croll (2009) documented that students from low SES backgrounds were less likely to stay in post-compulsory education even when accounting for attainment (and low attaining students even less likely to stay on in education). Suggested reasons for this too are that these students were unsure of what post-compulsory education meant to them, how to do it and what the options were. This cycle of less education and a less desirable job is easily repeated over generations.

Post-compulsory is the key term here and many students choose non-science subjects, if they study post-16, and it is not the purpose here to try to make them choose science. Rather, the argument is that all students should be able to engage with and learn from the compulsory science education up to and including age 16 (in England) and then make informed decisions about whether to continue with science in the post-compulsory phase. Attempts in England in the 2006 science curriculum reforms seemed to have had partial success in designing a school science course, called Core Science, that was intended as science for all, not just for scientists. The majority of science qualifications for students aged 14-16 were to have this one part that, in addition to key science concepts, focused on science in society to try to make the population more scientifically literate. Some students who took an applied course alongside this, in their final year of compulsory schooling (more likely for students from lower SES backgrounds), recognised the value of this particular course in that it was linked to their lives and was perceived to have some purpose (Banner and Ryder 2014). Students also appreciated continuous assessment elements that were more suited to their ways of working. However, this course was dropped a couple of years later after the next UK government decided that the applied science qualification 
would not be valued as science in the then new public accountability measures. Now the government once again is focusing on a science education for future scientists for the economic benefit of the country and as such it could be argued that it is also maintaining the elite social structure with science for the few and not for the many (Bencze 2010). The previous curriculum was not wholly successful in its mission; some students taking two applied courses (and not the Core Science course) who were asked about the relevance of school science to their lives still felt that they were learning science for future scientists and therefore it was not relevant to them (Banner and Ryder 2014). The importance of teachers and teaching in this, and in much data related to students' school experiences and choices, should not be underestimated (ibid). However, the evidence from the EISER project suggested that a curriculum can be designed to make school students' cultural border crossing easier, by changing a "deficit learning discourse" (Harper 2015, p. 6), based in the dominant middle class culture of science, to one where everyday knowledge and experiences of all families is acknowledged and shared.

\section{Identity as a science learner}

Students and their families may also have high expectations "eroded by negative experience" (Carter-Wall and Whitfield 2012, p. 4). These may come from schools and teachers, not necessarily an intentional marginalisation of students from poorer backgrounds but in a failure to see the importance in giving students a can-do approach to (science) education. There is a cultural discourse that pervades school science, from staff as well as students, that science is hard and only for (naturally) clever people (Archer et al. 2010); this can easily lead to the well-documented 'not for me' identity even among those students who enjoy science lessons in school. Science identity is formed initially by a mixture of background and upbringing and reinforced (or not) by teachers' responses to that developing identity, where for example girls may not be as challenged as boys are when questioned due to lower expectations from teachers (Brickhouse et al. 2000). In a summer programme for school students, designed to encourage them to consider a career in science and related areas, Lee (2002) found that it was more successful with girls than boys. This was explained by boys having more durable and stable identities, indicating that girls' views about themselves can be influenced.

Barton et al. (2008) talk about identities as being multiple and flexible; students from poor backgrounds were allowed the freedom to learn science by completing tasks using capabilities and proficiencies that they had outside the classroom (e.g. presenting work as a pop song or a rap). This meant, like Karen parents becoming actors instead of victims, school students were experts rather than novices. These students could develop new and temporary identities that allowed them to link their lived worlds and the science classroom. Identity is closely linked to knowledge and understanding of the relevance of science to a range of careers (as discussed previously) and seeing or learning about people from a wide range of jobs and careers using science to a lesser or greater extent is likely to reduce feelings of exclusion (Jonathan Osborne and Dillon 2008). However, exposing school students to a narrow range of university science students perhaps could be detrimental. In one study, students from a regional comprehensive school were taken to meet medical students in the local university. The university students were not from that area of the country and none in the group had any regional accents. After a few hours of talks and questions and answers, school students returned to school thinking that medicine at 
university was not for them (pers. comm.). Other negative experiences that may impact on future science participation might be as a result of what students perceive to be bad teaching or teachers (J. Osborne et al. 2003).

\section{Teachers and teaching}

Teachers have an important role to play in facilitating students' cultural border crossings and encouraging a version of students' identities that allows them to see science as an option for them in the future. This might be in the shape of supporting the border crossing and reducing the magnitude of the border that some children have to cross. As discussed above, teachers can allow students to be proficient at a method of presenting and explaining science to give them a way into the school science 'world'. The pedagogies which teachers may use to encourage students to find meaning in science and engage with it are well-known but perhaps still not widely used, for example, different methods based in social constructivism (Driver et al. 1994). Patchen and Cox-Petersen (2008) discuss some links with this and a different approach called culturally relevant pedagogy where typical power relationships between teacher and students are re-thought and where links between home and school are reinforced. This approach has commonalities with social constructivism and a positive attitude towards and use of the home language to help teach difficult science concepts is seen by the authors as a method of increasing successful border crossing with otherwise marginalised students. It is thought, though, that teachers may feel as if they have not got the knowledge or skills to be able to use approaches like this (ibid.).

There are also calls for changes of the focus in curricula, for science to be made relevant to students' lives. Relevant content taught in context-based science lessons has been an approach designed to engage students in their science learning. Some studies have shown that a contextualised approached, maybe featuring a local issue, has increased attainment in and positive attitudes towards school science (M. K. Lee and Erdogan 2007), although the actual effect of this in terms of changes in behaviour might be harder to show (Kanter and Konstantopoulos 2010). This might be hindered further by assessment practices, which do not encourage knowledge in contextualised situations, as well as unclear understandings of what contextualised science means, by teachers and parents as well as students (Tytler et al. 2008).

A step further is perhaps to reconsider the identity of science education, not just by contextualising the same content but rather by seeing it as a way of teaching science skills and processes, approaches to research, evidence and so on. This might be by engaging students in local projects so that they are genuinely contributing to finding a solution (Tytler et al. 2011). It might be about changing what science means to students by making school science all about creativity, collaboration and innovation, things that students feel are important in their lives now (Schreiner and Sjoberg 2007). In some ways this is encouraging students to feel that their lives are relevant to learning science, which may be more empowering than the discourse that tries to make science more 'relevant' to them. This is about answering questions about the purposes of a science education and at whom it is aimed in a rapidly changing (science) world. Arguments for the varying purposes are persuasive, particularly perhaps those that recognise the changing nature of society and the perceived need for a population who can access and understand how science works rather than remembering a list of facts about what things are called and what they do (Millar and Osborne 1998). However, designing a single curriculum for the many (who do not go on to 
become scientists) and for the few (who do) may seem to be something that is hard to reconcile (Ryder and Banner 2010), and perhaps pedagogy and the talk in the classroom around science as being say, useful or relevant are more important that the curriculum itself (Tytler 2007).

It is important that teachers are honest about science and what learning science is for, to broaden its appeal and relevance to their students; science is sometimes 'sold' negatively, without science you can't be a nurse, as opposed to being a positive thing such as with science you can do many things (DeWitt et al. 2013). However, there are some limitations to the push towards engaging students with school science for careers. This instrumental approach is fine with a minority of students who want to do something in their future that they perceive is (linked to) science but for those who don't this could cause further alienation. The different purposes of science education (e.g. Millar 1996) are perhaps not considered enough: the cultural achievement of humans in their explorations and explanations of the world around us, so students appreciate the wonder of science rather like they might appreciate art and music — this emphasis could make links between students and school and thus border crossing should be less difficult (Claussen and Osborne 2013); although teachers would need to find ways of getting away from old white males from the western world. Science is also a subject where processes such as observation, perseverance, analysis and recognition of relationships to draw conclusions are important in furthering knowledge in the science sphere as well as for non-science related citizenship (Claussen and Osborne 2013). An emphasis on what can be learnt about these things and how they might be useful or relevant is likely to resonate with a larger group of students.

\section{Concluding thoughts}

The differences between small communities of Karen refugees in USA and a large group of marginalised people in their own country are sizeable, many and varied which means that encouraging meaningful learning in school science will not work in exactly the same way. However, this doesn't prevent thinking about creating a cross-cultural learning community by acknowledging that cultural border crossing is difficult for many students trying to fit into the school science world. Developing and maintaining a positive science identity, which may not fit with other personal identities or with the view of teachers and other significant adults, also needs to be understood so as at least to challenge assumptions that can be made by students, their families and teachers when negotiating school science culture. Students should be given opportunities in school to make connections between what they already know (outside school and not necessarily science) and with what they need to know-a natural extension of social constructivism but broadened to beyond science content and process (Barton et al. 2008). Parents of children from low SES backgrounds in their own country, for example, may genuinely not have a link to school science, including horticulture and other more applied subjects. However, involving parents in some forms of meaningful science education, perhaps in after-school or out-of-school settings, to help plan, manage or contribute towards sessions may break down cultural barriers between home and school, and life-worlds and science-worlds. This signals that the school does not view families with low science capital as a problematic issue to overcome but creates a culture of reciprocity of learning that celebrates diverse knowledge and culture as a part of learning.

Open Access This article is distributed under the terms of the Creative Commons Attribution 4.0 International License (http://creativecommons.org/licenses/by/4.0/), which permits unrestricted use, distribution, 
and reproduction in any medium, provided you give appropriate credit to the original author(s) and the source, provide a link to the Creative Commons license, and indicate if changes were made.

\section{References}

Aikenhead, G. (1996). Science education: Border crossing into the subculture of science. Studies in Science Education, 27(1), 1-52.

Aikenhead, G. (1997). Toward a first nations cross-cultural science and technology curriculum. Science Education, 81(2), 217-238.

Aikenhead, G., \& Jegede, O. (1999). Cross-cultural science education: A cognitive explanation of a cultural phenomenon. Journal of Research in Science Teaching, 36(3), 269-287.

Archer, L., DeWitt, J., Osborne, J., Dillon, J., Willis, B., \& Wong, B. (2010). "Doing” science versus "being" a scientist: Examining 10/11-year-old schoolchildren's constructions of science through the lens of identity. Science Education, 94(4), 617-639. doi:10.1002/sce.20399.

Archer, L., DeWitt, J., Osborne, J., Dillon, J., Willis, B., \& Wong, B. (2012). Science aspirations, capital, and family habitus: How families shape children's engagement and identification with science. American Educational Research Journal, 49(5), 881-908. doi:10.3102/0002831211433290.

Aschbacher, P. R., Li, E., \& Roth, E. J. (2010). Is science me? High school students' identities, participation and aspirations in science, engineering, and medicine. Journal of Research in Science Teaching, 47(5), 564-582. doi:10.1002/tea.20353.

Banner, I. (in prep). Student interest in interventions: Understanding the uptake of post-compulsory physics.

Banner, I., \& Ryder, J. (2014). The impact of a context-led curriculum on different students' experiences of school science. In C. Bruguière, A. Tiberghien, \& P. Clément (Eds.), Topics and trends in current science education (Vol. 1, pp. 369-383). Contributions from Science Education Research). Dordrecht: Springer.

Barton, A. C., Tan, E., \& Rivet, A. (2008). Creating hybrid spaces for engaging school science among urban middle school girls. American Educational Research Journal, 45(1), 68-103. doi:10.3102/ 0002831207308641.

Bencze, J. (2010). Exposing and deposing hyper-economized school science. Cultural Studies of Science Education, 5(2), 293-303. doi:10.1007/s11422-010-9256-8.

Bourdieu, P. (1977). Outline of a theory of practice. Cambridge: Cambridge University Press.

Brickhouse, N., Lowery, P., \& Schultz, K. (2000). What kind of a girl does science? The construction of school science identities. Journal of Research in Science Teaching, 37(5), 441-458.

Buldu, M. (2006). Young children's perceptions of scientists: A preliminary study. Educational Research, 48(1), 121-132. doi:10.1080/00131880500498602.

Carter-Wall, C., \& Whitfield, G. (2012). The role of aspirations, attitudes and behaviours in closing the educational attainment gap. York: Joseph Rowntree Foundation.

Claussen, S., \& Osborne, J. (2013). Bourdieu's notion of cultural capital and its implications for the science curriculum. Science Education, 97(1), 58-79. doi:10.1002/sce.21040.

Croll, P. (2009). Educational participation post-16: A longitudinal analysis of intentions and outcomes. British Journal of Educational Studies, 57(4), 400-416. doi:10.1111/j.1467-8527.2009.00445.x.

Department for Education. (2015). School workforce in England: Statistical first release. London: Department for Education.

DeWitt, J., Osborne, J., Archer, L., Dillon, J., Willis, B., \& Wong, B. (2013). Young children's aspirations in science: The unequivocal, the uncertain and the unthinkable. International Journal of Science Education, 35(6), 1037-1063. doi:10.1080/09500693.2011.608197.

Driver, R., Asoko, H., Leach, J., Mortimer, E., \& Scott, P. (1994). Constructing scientific knowledge in the classroom. Educational Researcher, 23(7), 5-12.

Gutman, L., \& Akerman, R. (2008). Determinants of aspirations [wider benefits of learning research report no. 27]. London: Centre for Research on the Wider Benefits of Learning, Institute of Education, University of London.

Harper, S. (2015). Keystone characteristics that support cultural resilience in Karen refugee parents. Cultural Studies of Science Education. doi:10.1007/s11422-015-9681-9.

Haug, B., \& Ødegaard, M. (2014). From words to concepts: Focusing on word knowledge when teaching for conceptual understanding within an inquiry-based science setting. Research in Science Education, 44(5), 777-800. doi:10.1007/s11165-014-9402-5.

Homer, M., Ryder, J., \& Donnelly, J. (2011). The use of national data sets to baseline science education reform: Exploring value-added approaches. International Journal of Research \& Method in Education, 34(3), 309-325. doi:10.1080/1743727x.2011.609544. 
Homer, M., Ryder, J., \& Donnelly, J. (2013). Sources of differential participation rates in school science: The impact of curriculum reform. British Educational Research Journal, 39(2), 248-265. doi:10.1080/ 01411926.2011 .635783 .

JCQ. (2014). Examination results: A-levels (August 2014 ed.). London: Joint Council for Qualifications.

Kanter, D. E., \& Konstantopoulos, S. (2010). The impact of a project-based science curriculum on minority student achievement, attitudes, and careers: The effects of teacher content and pedagogical content knowledge and inquiry-based practices. Science Education, 94, 855-887. doi:10.1002/sce.20391.

Kintrea, K., St. Clair, R., \& Houston, M. (2011). The influence of parents, places and poverty on educational attitudes and aspirations. York: Joseph Rowntree Foundation.

Lee, J. D. (2002). More than ability: Gender and personal relationships influence science and technology involvement. Sociology of Education, 75(4), 349-373. doi:10.2307/3090283.

Lee, M. K., \& Erdogan, I. (2007). The effect of science-technology-society teaching on students' attitudes toward science and certain aspects of creativity. International Journal of Science Education, 29(11), 1315-1327. doi:10.1080/09500690600972974.

Millar, R. (1996). Towards a science curriculum for public understanding. School Science Review, 77(280), 7-18.

Millar, R., \& Osborne, J. (Eds.). (1998). Beyond 2000: Science education for the future. London: King's College London, School of Education.

Mujtaba, T., \& Reiss, M. J. (2013). Inequality in experiences of physics education: Secondary school girls' and boys' perceptions of their physics education and intentions to continue with physics after the age of 16. International Journal of Science Education, 35(11), 1824-1845. doi:10.1080/09500693.2012. 762699.

Osborne, J., \& Dillon, J. (2008). Science education in Europe: Critical reflections (Vol. 13). London: The Nuffield Foundation.

Osborne, J., Simon, S., \& Collins, S. (2003). Attitudes towards science: A review of the literature and its implications. International Journal of Science Education, 25(9), 1049-1079.

Patchen, T., \& Cox-Petersen, A. (2008). Constructing cultural relevance in science: A case study of two elementary teachers. Science Education, 92(6), 994-1014. doi:10.1002/sce.20282.

Royal Society. (2011). Preparing for the transfer from school and college science and mathematics education to UK STEM higher education: A 'state of the nation' report. London: Royal Society.

Ryder, J., \& Banner, I. (2010). Multiple aims in the development of a major reform of the national curriculum for science in England. International Journal of Science Education, 33(5), 709-725. doi:10. 1080/09500693.2010.485282.

Schibeci, R. A. (2006). Student images of scientists: What are they? Do they matter? Teaching Science, $52(2), 12-16$.

Schreiner, C., \& Sjoberg, S. (2007). Science education and youth's identity construction-Two incompatible projects? In D. Corrigan, J. Dillon, \& R. Gunstone (Eds.), The re-emergence of values in the science curriculum. Sense: Rotterdam.

Scott, P., Asoko, H., \& Leach, J. (2007). Chapter 2: Student conceptions and conceptual learning in science. In S. K. Abell \& N. G. Lederman (Eds.), Handbook of research on science education (p. ix). Mahwah, $\mathrm{NJ}$; London: Lawrence Erlbaum.

Smith, E., \& Gorard, S. (2011). Is there a shortage of scientists? A re-analysis of supply for the UK. British Journal of Educational Studies, 59(2), 159-177. doi:10.1080/00071005.2011.578567.

Strand, S. (2007). Minority ethnic pupils in the longitudinal study of young people in England (LSYPE) (p. 6). Nottingham: DfES.

Tytler, R. (2007). Re-imagining science education: Engaging students in science for Australia's future. Victoria: Australian Council for Educational Research.

Tytler, R., Osborne, J., Williams, G., Tytler, K., \& Cripps Clark, J. (2008). Opening up pathways: Engagement in STEM across the primary-secondary school transition. Melbourne: Australian Department of Education, Employment and Workplace Relations.

Tytler, R., Symington, D., \& Smith, C. (2011). A curriculum innovation framework for science, technology and mathematics education. Research in Science Education, 41(1), 19-38. doi:10.1007/s11165-0099144-y.

Indira Banner is a Lecturer in Science Education in the School of Education at the University of Leeds, UK, conducting research and teaching on post-graduate courses for initial and continuing teacher education. Her main areas of research are looking at students' experiences of and encouraging equality in school science. 